\title{
Human health risk assessment of selected endocrine disrupting phenolic compounds in potable water and treated wastewater effluent in the Western Cape, South Africa
}

\author{
NL Mhlongo \\ Faculty of Applied Sciences, Cape Peninsula University of Technology, PO Box 652, Cape Town \\ 800, South Africa
}

\begin{abstract}
Water resources are under threat by industrial and agricultural pollution due to the release of organic contaminants such as phenol into water bodies. This reduces water quality, thereby decreasing the availability of clean water. Samples of the Stellenbosch wastewater treatment plant effluent tap water, and four brands of bottled water were analyzed for the two phenolic compounds; 4-CP and 2,4-DCP using the HPLC/DAD. The phenolic compounds were both below the regulatory limits in all the samples analyzed. The concentrations of 2,4-DCP in the WWTP effluent, tap water and bottled water brands 'A', 'B', 'C'and 'D' ranged from; ND$5.40 \times 10^{-6}$, ND- $1.90 \times 10^{-5}$, ND-1.31 $\times 10^{-5}, 3.68 \times 10^{-6}-1.37 \times 10^{-5}$, ND- $6.85 \times 10^{-6}$ and $6.28 \times 10^{-6}$ $-1.47 \times 10^{-5}$ respectively. Corresponding values for 4 -CP were $4.04 \times 10^{-6}-5.61 \times 10^{-5}, 9.96 \times 10^{-6}$

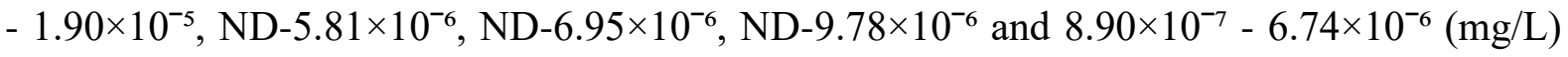
respectively.
\end{abstract}

Keywords: Endocrine disruptors, 4-CP, 2,4-DCP, waste water effluent, bottled water, tap water 